\title{
Especulações acerca das possíveis origens indígenas da capoeira e sobre as contribuições desta matriz cultural no desenvolvimento do jogo-luta
}

CDD. 20.ed. 796.82

Ricardo Martins Porto LUSSAC ${ }^{*}$

*Universidade do Estado

do Rio de Janeiro.

http://dx.doi.org/10.1590/1807-55092015000200267

\section{Resumo}

A origem da Capoeira tem sido investigada e discutida até os dias atuais. Vários pesquisadores de diversos campos e, inclusive, os próprios capoeiristas discordam quanto à sua gênese. Estas dicotomias persistem em embates no campo da Capoeira. Neste artigo foram analisadas, interpretadas e discutidas as possibilidades das origens indígenas da Capoeira, e as possíveis contribuições dos índios brasileiros no desenvolvimento do jogo-luta. Por meio das análises realizadas, foi possível elaborar especulações e apontamentos gerais sobre 0 assunto. A pesquisa tem um enfoque histórico. Foi utilizada como procedimento metodológico a pesquisa bibliográfica e documental, tendo-se realizado análise qualitativa das fontes que foram interpretadas e discutidas ao longo da narrativa deste trabalho. Constatou-se que houve a possibilidade de interação entre negros e índios em trocas culturais que possibilitariam influências no desenvolvimento da Capoeira. Entretanto, concluiu-se que não é possível afirmar existirem diretamente contribuições indígenas brasileiras para as origens da Capoeira. Destarte, é possivel afirmar que a única e importante contribuição indígeno-brasileira é a origem nominal da prática, por ser o vocábulo capoeira de origem tupy. Recomenda-se que futuros estudos sejam realizados aproveitando os apontamentos realizados neste artigo e analisando as fontes primárias que não foram possiveis constar no rol documental deste trabalho.

Palavras-Chave: Capoeiragem; Gênese; História; Índios; Jogo; Luta.

\section{Introdução}

Até pouco tempo, as origens da Capoeira ainda eram uma incógnita ${ }^{1}$. Mas mesmo com o avanço das pesquisas, este ainda é um tema "complexo demais para ser dirimido em poucas palavras" (p. 576). A gênese do jogo-luta tem sido investigada por pesquisadores de diferentes áreas, mais recentemente: Assunção ${ }^{3}$, Desch Obi ${ }^{4}$ e Soares ${ }^{2,5}$, da História; LOPES $^{6}$, da Administraçáo e Jornalismo; PAssos $\mathrm{NeTO}^{7}$, da Comunicação; VIeIrA ${ }^{8-11}$, da Sociologia; Araújo ${ }^{12}$, da Educação Física; e o próprio autor deste trabalho; entre outros.

Sobre o assunto há diversas especulações e hipóteses despertando várias interpretaçóes e discursos, tendenciosos ou não, de diferentes grupos, gerando algumas vezes mitos, semi-verdades e controvérsias. Na maioria das vezes, tais discursos tentam fortalecer os interesses e a sustentaçáo de uma criaçáo apaixonada ou idealizada por determinados grupos com interesses próprios ${ }^{13}$. Mas mesmo sendo o assunto da origem da Capoeira já vastamente abordado, é possível identificar que vários pesquisadores e capoeiristas discordam quanto à sua gênese: africana ou brasileira; negra escrava, liberta ou livre; indígena ou mestiça; camponesa, rural ou urbana; de Salvador - BA ou do Rio de Janeiro - RJ. Estas dicotomias persistem em embates no campo da Capoeira.

A Capoeira, mesmo que tenha tido uma matriz estrangeira, originou-se realmente no Brasil ${ }^{1}$. É possível afirmar que a dificuldade em pesquisar a origem, o desenvolvimento e a história da Capoeira não está exclusivamente em sua gênese, mas sim na diversidade que a compóe ${ }^{1}$.

Por ser o tema da origem da Capoeira complexo demais é natural não acreditar em uma possível e simples transladação de uma expressão estrangeira para o Brasil, como já afirmou SoAREs ${ }^{2}$. Neste caso, a 
formação do jogo-luta ocorrido em terras brasileiras, com todas as trocas e influências culturais, se torna complexo, existindo inúmeros fatores e variáveis durante todo o seu desenvolvimento, que devem ser considerados ${ }^{1}$. Neste sentido, náo é possível descartar contribuiçóes oriundas dos povos indígenas brasileiros. Deste modo, por ainda haver uma

\section{Método}

A pesquisa tem um enfoque histórico. Foi utilizada como procedimento metodológico a pesquisa bibliográfica e documental, tendo-se realizada análise qualitativa das fontes que foram interpretadas e discutidas ao longo da narrativa deste trabalho.

Diversas fontes bibliográficas foram utilizadas como pressuposto teórico, não só devido à abrangência da pesquisa, mas também pelo motivo de que muitas destas fontes, em sua grande maioria, não abordam o assunto especificamente. A única publicação neste sentido é a matéria de uma revista especializada em Capoeira ${ }^{14}$, que liga a origem brasileira do jogo-luta às matrizes indígenas brasileiras.

Sobre a história da Capoeira no século XIX esta pesquisa se apoiou nos estudos de SoAres ${ }^{2,5}$ e de Araújo ${ }^{12,15}$, autores que, em razão de contribuiçóes relevantes para a historiografia, serviram como base nesta investigação.

$\mathrm{Na}$ realização desta pesquisa, não foi possível analisar algumas fontes primárias como, por exemplo, os Tomos dos Jesuítas que repousam na Torre do Tombo em Lisboa, Portugal, e em outros locais na Europa. Deste modo, a fim de oferecer maiores contribuiçôes para a área, recomendo que futuros estudos aproveitem os apontamentos realizados neste artigo ao analisar as fontes primárias que não foram possíveis constar no rol documental deste trabalho.

As fontes primárias utilizadas neste trabalho foram documentos encontrados no sítio de Internet Brasiliana da USP, pelo qual foi possível obter cópia

\section{Resultados e discussão}

De acordo com o mestre de Capoeira Gladson Silvi ${ }^{19}$, no livro do padre José de Anchieta, Arte de gramática da língua mais usada na costa do Brasil, impressa em Coimbra em 1595 - a segunda obra do padre e a primeira gramática contendo os lacuna no meio acadêmico sobre uma discussão mais aprofundada sobre o assunto, este artigo tem como objetivo elaborar especulaçóes e apontamentos gerais por meio de analises, interpretaçóes e discussões sobre as possibilidades que sugerem as origens indígenas da Capoeira, e as possíveis contribuiçóes destes povos no desenvolvimento do jogo-luta.

digitalizada de dois volumes ${ }^{16-17}$ de um dicionário do final do século XVIII. Também foi utilizado um Códice $^{18}$ do início do século XIX, que repousa no Arquivo Nacional, no qual está presente a primeira fonte de evidência do jogo-luta da Capoeira na História, até o momento encontrada.

Os referenciais teóricos foram analisados por meio de interpretaçôes de suas diferentes abordagens e enfoques, buscando as contribuiçôes científicas que estes puderam somar. As fontes tiveram um tratamento qualitativo e interpretativo, e o cuidado de uma crítica interna referente ao conteúdo e significado da fonte ou documento, com o objetivo de verificar até que ponto apresentam coerência com as informaçóes sobre o mesmo fato ou fenômeno colhidos em outras fontes, ao mesmo tempo em que se buscou entender o diálogo construído entre as fontes. A construção e a exposição dos argumentos foram desenvolvidas e apresentadas, relacionando os diferentes elementos e acontecimentos, obedecendo a uma sequência e encadeamento lógico.

Os marcos temporais deste trabalho abarcam o período compreendido entre o descobrimento do Brasil e o século XIX, e a delimitação espacial abrangeu o território brasileiro. O recorte temporal deste artigo foi definido por no início deste período serem encontradas fontes que sustentariam algumas especulaçôes sugeridas neste trabalho. Já durante o século XIX é verificado um grande número de fatores que contribuíram para o desenvolvimento da Capoeira, dentre eles, possíveis contribuiçôes dos índios brasileiros.

fundamentos da língua tupy, também sendo a segunda obra dedicada a línguas indígenas na América - há uma citação que "os índios tupi-guaranis divertiamse jogando capoeira” (p.10) ${ }^{19}$. Mestre Gladson também afirma em sua obra que "o navegador 
português Martim Afonso de Souza teria observado tribos jogando capoeira" (p.10) ${ }^{19}$. De acordo com as referências acima, tanto o padre jesuíta como Martim Afonso de Sousa atestam a Capoeira que observaram como um jogo, em que o padre ainda descreve acrescentando que se divertiam, porém não sendo citada nenhuma relação destes jogos com algum tipo de música ou luta. Tais relatos possivelmente estariam descrevendo algum tipo de brincadeira jogada na mata capoeira e não necessariamente a Capoeira luta, prática corporal. Mas o fato é que, por estas referências se pode considerar a existência de algum tipo de expressão com a presença do elemento jogo sendo praticada na mata, na capoeira, ou mesmo alguma prática lúdica nomeada capoeira pelo padre ou mesmo pelos índios. Mas, do mesmo modo, se deve considerar que se esta fosse uma prática cultural mais específica, poder-seia crer que o padre jesuíta, pelo grande tempo de observação, pelas várias regióes em que passou e devido ao tipo de relacionamento que manteve com os índios, não se deteria em fornecer maiores detalhes. Afinal, o padre foi um dos portugueses que melhor conheceram o litoral sudeste do Brasil: Sáo Paulo, Rio de Janeiro e Espírito Santo - e ainda esteve brevemente na capitania da Bahia. Soma-se a isto o fato de sua diferenciação da maior parte dos demais pela sua cultura erudita naquele período, compreendido entre 1553, quando chegou ao Brasil com 19 anos de idade, até o seu falecimento em 1597. José de Anchieta cultivou quatro línguas: português, castelhano, latim e tupy, e produziu importantes obras, as quais ainda merecem maiores análises para estudos relacionados à Capoeira.

Análises mais profundas sobre tais documentos, combinadas com outros estudos relativos podem contribuir de alguma forma sobre o assunto, mas as leituras superficiais feitas até agora sobre tais referências tornam inconclusivas maiores especulaçóes. Outro ponto é a análise na fonte primária, a qual não foi possível o acesso durante a elaboraçáo deste estudo e que pode ser julgada como sendo preponderante para investigaçóes mais profundas no futuro, aproveitando os apontamentos desenvolvidos por este trabalho.

Sobre Martim Afonso de Sousa, este foi um nobre e militar português, nascido entre 1490 e 1500, tendo falecido em 21 de julho de 1564 ou 1571. Após o início de sua carreira de homem de mar e guerra, em 1531 percorreu todo o litoral brasileiro por ocasião da armada que o Rei D. João III enviou ao Brasil para estabelecer posses na área da bacia do Rio do Prata, o que náo aconteceu devido ao seu naufrágio. Após este fato retornou à região de São Vicente em 1532, onde estreitou laços com lideranças indígenas locais e fundou no mesmo ano a primeira vila dos portugueses nas Américas - a Vila de São Vicente. Desta viagem, resultou o Diário da navegação de Pero Lopes de Sousa - irmão de Martim - um documento histórico ímpar publicado somente no século XIX, e que merece uma análise em futuros estudos por concorrer como uma possível fonte para a história da Capoeira. Posteriormente, Martim Afonso de Sousa retornou a Lisboa em 1534, já como Capitáo-Mor e donatário de duas capitanias hereditárias. Deste modo, torna-se possível inferir que é grande a possibilidade de Martim Afonso de Sousa ter tido contato com a Capoeira, ou algo semelhante, se esta fosse parte da cultura indígena e se existisse sua ocorrência no litoral Sul-Sudeste e talvez no Nordeste naquele período. E por ser Capitão-Mor, de certo modo centralizava as informaçóes da Colônia, sendo que se a Capoeira ou outra expressão semelhante fosse utilizada como instrumento de defesa, resistência ou rebelião de alguma forma, provavelmente, ele teceria maiores detalhes sobre esta prática.

Já Guilherme de Almeida: "no livro 'Música no Brasil', sustenta serem indígenas as raízes da capoeira" (p.10) ${ }^{19}$, provavelmente devido a alguma relação quanto à musicalidade destas, o que os estudiosos no campo da etnomusicologia poderiam informar melhor. Talvez maiores esclarecimentos sobre o ponto de vista do autor possam elucidar tal afirmação, ou corroborar maiores análises. Mas é necessário afirmar que tal análise não pode ser anacrônica ou linear, por Guilherme de Almeida estar se referindo às raízes da música observada nos tempos modernos da Capoeira. Neste sentido, também é imprudente descartar as raízes africanas na composição da música da Capoeira. Náo se pode esquecer que no primeiro foco de eclosáo da Capoeira verificado até o momento, no caso o Rio de Janeiro, sua prática, até onde se sabe, nem sempre era acompanhada especificamente por música, apesar da prática da Capoeira ocorrer por diversas vezes em proximidades ou juntos com os batuques e lundus, de acordo com Ribeyrolles ${ }^{20}$ (p.37), perfazendo um conjunto de práticas sociais com ênfase maior da presença de negros, ou mesmo tendo sido verificada a presença de um tambor na litografia Jogar Capoeira de Rugendas, elaborada na terceira década do século XIX, e descrita como prática de negros pelo artista ${ }^{21}$. Isso talvez ocorresse pelo fato de a Capoeira carioca, desde o início de sua verificação no início da segunda década do século XIX, até antes de 1950 - começo da influência de baianos radicados no Rio - nem sempre apresentar acompanhamento musical específico, como já afirmado, pelo fato da severa repressão, onde 
sua prática como jogo, se fosse acompanhada de música e canto, seria mais facilmente e rapidamente identificada e, logo, reprimida.

O pesquisador Luiz Carlos Krummenauer Ro$\mathrm{CHA}^{14}$ fornece outras pistas relativas à possibilidade da origem indígena da Capoeira, quando cita as cartas para Portugal e Espanha dos anais das missóes jesuíticas no Brasil:

Cartas; do jesuíta Antônio Gonçalves para os superiores em Lisboa, em 1735, descreve uma luta em que os índios praticavam antes de qualquer conflito, em forma de dois a dois ao centro usando os braços e as pernas como armas (Convento de Santo Inácio de Loyola, anais das missões no Brasil. Tomo III p128) (p.11) ${ }^{14}$. O jesuíta padre MANOEL DA NÓBREGA descreve em suas cartas ao seu superior na Espanha falando dos costumes indígenas, descrevendo a agilidade dos índios Potiguaras com os pés, mãos e cabeçadas, transformando-se em arma perigosa. $\mathrm{O}$ "museu do convento dos Jesuítas de Barcelona - Tomo VII de 1860, em Latim" (p.13) ${ }^{14}$.

Destarte, descrever uma prática com dois sujeitos utilizando braços e pernas como armas é tão genérica que se pode imaginar desde uma prática semelhante à Capoeira a práticas semelhantes ao judô ou ao Huca Huca.

Já a descrição do padre jesuíta Manoel da Nóbrega sobre a prática dos índios Potiguara é interessante quando descreve que estes também usavam a cabeça como uma arma ágil e perigosa. A cabeçada é uma expressão motora muito encontrada nos relatos mais antigos sobre a prática do jogo-luta, mas é necessário ter o cuidado para não tecer análises lineares com a prática da Capoeira. Talvez o padre estivesse se referindo à maraná dos Potiguara. Também são curiosas a avançada data do Tomo, 1860, e a data da carta, 1735 - 24 anos antes da expulsão dos jesuítas do Brasil pelo Marquês de Pombal. Talvez se possa vislumbrar uma possibilidade dos potiguaras terem levado algum tipo de técnica de luta e combate, para além de seu território originalmente ocupado. De origem tupy, é sabido que este povo estabeleceu alianças com ingleses e franceses na exploração do pau-brasil, deste modo, resistindo um bom tempo contra investidas ibéricas, talvez daí sua fama guerreira.

Estas descrições oferecem poucas evidências para elar qualquer tipo de prática de luta à Capoeira. Maiores informaçóes sobre estes tipos de relato, como data ou período, local ou regiáo, entre outras, são cruciais para análises mais detalhadas. Novamente, a impossibilidade de acesso a estas fontes primárias não deixa ocorrer uma análise mais profunda, deste modo, sugerindo futuras pesquisas com estas fontes e outras mais.

RochA ${ }^{14}$ descreve também a maraná, antiga luta e ritual dos índios Potiguara, que "no dicionário tupiguarani significa dança de guerra" (p.12) ${ }^{14}$. RochA ${ }^{14}$ fornece outra boa fonte que merece maior atenção para futuras pesquisas, a descrição da maraná pelo escritor holandês Gaspar Barleus, o qual descreve "no livro 'Rerum Per Octennium in Brasília - 1647, a luta dos índios tupis praticadas no litoral brasileiro' [sic] chamado de Maraná, luta de guerra, só existem dois exemplares, um nos EUA e outro no Brasil" (p.11) ${ }^{14}$. Com certeza uma análise mais densa sobre esta fonte primária seria interessante. A seguir uma descrição da maraná, de 1670:

O cronista alemão Johann Nieuhoff descreve em seu livro "Crônicas do Brasil Holandês" 1670, a luta da Maraná assim como descrevo abaixo: Maraná

As cartas do escrivão Francis Patris, que acompanhava o cortejo do príncipe Maurício de Nassau durante a invasão holandesa, descreve entre muitos obstáculos para a ocupação do território brasileiro a resistência dos habitantes do Brasil. Negros comandados por Henrique Dias, portugueses por Vidal de Negreiros, Índios Potiguaras comandados por Felipe Camarão, o "índio Poti”. Estes índios usavam durante o confronto, além de flechas, borduna, lanças e tacapes, os pés e as mãos deferindo golpes mortais, destacandose por sua valentia e ferocidade.

Pertencia à cultura potiguara a dança de guerra Maraná, que avaliava o nível de valentia. Em círculo, os guerreiros com perneiras de conchas compunham um compasso ao bater com os pés e as mãos, invocando seus antepassados, acompanhado de atabaques de troncos com pele de anta, chocalhos e marimbas, enquanto que dois guerreiros ao centro com golpes de pernas, cotoveladas e movimento que imitava os animais (p.11) ${ }^{14}$.

É curiosa a utilização do passado como tempo verbal pelo cronista ao se referir às cartas do escrivão, já que este também poderia elaborar a sua narrativa em seu tempo presente. Deste modo, parece estar se referindo a uma prática já extinta no ano de 1670. Mas é possível que Johann Nieuhoffa tenha escrito seu relato durante sua passagem pelo oriente, após sua permanência no Brasil, elaborando um relato de sua memória.

A presença da música com tambores na prática da maraná já é um elemento interessante para a análise. Mas, no entanto, não é possível estabelecer 
um elo musical com a Capoeira do início do século XX, muito menos com períodos anteriores. A descrição da maraná como uma espécie de dança pírrica com a presença de golpes com os pés é mais um outro elemento, mas que deve ser entendida como um ritual específico contextualizado em uma cultura própria. Como já afirmado anteriormente, nenhuns destes pontos podem ser conectados diretamente com a prática da Capoeira. Pode-se crer que a informação mais valiosa é o movimento que imitava os animais, com certeza, animais da fauna brasileira, mais especificamente da Mata Atlântica, no caso dos indígenas da costa do Brasil. Sabe-se que alguns golpes e gestos da Capoeira são inspirados em movimentos de animais, também presentes na fauna brasileira, sendo inclusive, a origem de algumas nomenclaturas de gestos, movimentos e golpes claramente ligados a estes animais. Como exemplo é possível citar: rabo-de-arraia, macaco, entre outros.

Não se pode de modo algum afirmar que a maraná era a Capoeira praticada antigamente. Mas é possível especular que a maraná pode ter sido uma das matrizes formadoras da Capoeira, também devido à proximidade entre índios e negros na referência acima, o que poderia sugerir uma troca e influências culturais, diversas influências estas, que já são mais que constatadas em várias dimensóes na formação cultural da sociedade brasileira. Mas do mesmo modo é difícil acreditar na comprovaçáo desta especulação, pois estudos futuros acabariam se deparando com a escassez de fontes, não chegando à identificação deste possível elo específico de ligação cultural.

Um fato que concorre à formação de outra especulação é a relativa proximidade do Quilombo dos Palmares e a região de ocupação holandesa no Brasil. Há uma ideia presente no imaginário e no campo da Capoeira que propóe ser o Quilombo dos Palmares o local onde a maraná haveria sido assimilada culturalmente pelos guerreiros de Palmares, somando esta à outra ideia, a de que com destruição do Quilombo, os quilombolas remanescentes haveriam dispersado um tipo de técnica de luta e de jogo que seria o embrião da luta e jogo da Capoeira, sendo conhecida mais tarde em vários pontos do Brasil. Mas é estranho pensar deste modo, quando se constata que a Capoeira começou a ser documentada ${ }^{18}$ no início do século XIX no Rio de Janeiro ${ }^{1-2}$, lugar distante do Quilombo, e posteriormente a este período em outros lugares do Brasil, que seriam mais próximos ao Quilombo, como Recife, em Pernambuco, e Salvador, na Bahia.

Várias outras lutas e rituais guerreiros, bem diferenciadas dos contextos ocidentais, eram e ainda hoje são praticadas por índios brasileiros, como a Huca Huca, praticada no Alto Xingu, muito diferente da luta Capoeira, por mais se assemelhar à luta livre, e por ser uma prática ritual de luta caracteristicamente de corpo-a-corpo e com finalidades específicas mais próxima do jogo-disputa, do que de um combate corporal com fins marciais. Muitas outras lutas ou expressóes podem ter influenciado ou terem sido reelaboradas por caboclos de determinadas regióes, como a agarre marajoara, luta originária da Ilha de Marajó, mas esta também é uma luta caracteristicamente de corpo-a-corpo.

Também foi citada nas referências que a maraná era uma luta praticada pelos índios tupys no litoral brasileiro, mais precisamente os Potis. Sabe-se que o litoral foi o princípio, a porta de entrada para a conquista do território brasileiro que se expandiu em direção ao interior, e região onde é verificado o maior declínio de população indígena e, consequentemente, das suas respectivas práticas culturais. Inclusive, estas culturas também poderiam ter desaparecido com a extinção de tribos inteiras, pois justamente os povos indígenas caracteristicamente guerreiros, considerados bárbaros e que não se deixaram cooptar pelo processo de aculturação próprio da colonização, foram os mais afetados pela ação de combate dos colonizadores. $\mathrm{Na}$ verdade, qualquer povo indígena que estivesse obliterando o caminho de expansão dos colonizadores corria risco, e neste caso, a questão da expansão territorial foi uma constante, por diversos motivos e necessidades da colonização. Geralmente os índios que não eram escravizados ou exterminados sobreviviam, em sua maioria, trabalhando em áreas agrícolas por troca de alimento e utensílios diversos, tendo modificado o seu "modus vivendi" $22-23$.

Um bom exemplo neste sentido é a Carta Régia de D. João $\mathrm{VI}^{22}$, datada de 13 de maio de 1808 , que colocou os índios botocudos na mira dos colonizadores. $\mathrm{O}$ governo joanino autorizou e incentivou uma guerra contra esses índios, que compreendiam bacuéns, crenaques e teuetes, e tinham esse nome em comum pela aparência decorrida da perfuração dos lábios e orelhas com acessórios arredondados. Este tipo de conduta institucional, permeada de violência e valendo-se por diversas vezes do extermínio como método, marcou as relaçóes na história entre o Estado e as populaçóes indígenas. A guerra contra os botocudos foi só mais um capítulo da expansão 'civilizatória' do domínio português sobre territórios e povos, um movimento de expansão em direção ao interior do país. Com a distribuição de terras para 
fazendas e consequente colonização, simultaneamente a um processo de escravização dos índios para trabalhos públicos nas capitais das províncias ou alistamento militar, esta guerra, que ocorreu principalmente em Minas Gerais, Espírito Santo e no Rio de Janeiro, conseguiu quase exterminar esses índios e sua respectiva cultura ${ }^{22}$.

É possível constatar em algumas obras de Rugendas ${ }^{21}$ a convivência entre negros e índios no mesmo ambiente social. Deste modo, é possível entender que realmente há uma possibilidade da troca de experiências e saberes culturais entre índios e negros quanto aos conhecimentos do jogo-luta. Esta possibilidade de troca aumenta entre os que serviam a Marinha e os que cumpriam pena em trabalhos forçados, como será discutido adiante. Neste sentido, estudos posteriores podem ser realizados na tentativa de obter indícios da presença de índios junto aos capoeiras presos no Rio de Janeiro, a partir de 1808, já estudados por SOARES ${ }^{2,5}$. Talvez os índios possam ter contribuído de alguma forma no desenvolvimento da Capoeira no Rio de Janeiro durante o século XIX.

As extinçōes de várias etnias indígenas provocam uma dificuldade em pesquisar as culturas dos mesmos, pois o conhecimento destas era transmitido essencialmente por via oral. Também se sabe que vários sítios arqueológicos foram desde a colonização destruídos, perdendo provas materiais, o que logicamente, é mais um entrave à pesquisa destas culturas. A destruição dos sambaquis é um exemplo neste sentido. Considerados riquíssimas fontes de pesquisa, os sambaquis queimados transformavamse em cal, sendo utilizado como argamassas para construçôes, entre outros, ainda na época da colônia.

Um aspecto relevante que merece reflexão é o fato de que qualquer tipo de ação causa uma reação, lei da física que pode ser aplicada em várias circunstâncias humanas, guardada as devidas consideraçóes. Neste caso, afirma-se que se havia uma forma de luta, de combate, de combater, como a Capoeira ou algo semelhante, esta faria com que também existissem formas de defesa a este tipo de expressão corporal, fazendo parte dos ritos de sobrevivência e da cultura, tanto de índios brasileiros, como de naçóes africanas, assim como também dos colonizadores, o que até hoje não foi verificado antes do século XIX e corrobora para a tese ${ }^{1}$ mais provável, a do desenvolvimento da Capoeira em território brasileiro ao longo da colonização e, provavelmente, após o início do século XIX. Conforme o comentário informal do historiador Luis Sérgio Dias, em outubro de
2008, ao autor deste trabalho, por ocasião de sua qualificação de dissertação de mestrado: "cada cultura engendra formas de luta”.

Por último, mais um dado interessante para a análise: de acordo com Rochi ${ }^{14}$, Antônio Moraes da Silva cita a "Luta da Capoeira", praticada por negros, mestiços e índios no Brasil, em seu livro "Dicionário da Língua Portuguesa" Lisboa - Typografhia Lacerdina - 1813 Tomo I p.343" (p.12) Seria uma informação valiosa se fosse possível saber como Antônio Moraes da Silva chegou a estas informações contidas em seu dicionário, se estas realmente existirem conforme afirma Rocha ${ }^{14}$. Este dado é importante no que se refere à presença de índios e mestiços em uma referência da Capoeira como luta no período dos primeiros registros desta expressão no Rio de Janeiro - em registros policiais e processos jurídicos - onde outras pesquisas ${ }^{2}$ entendem haver quase um exclusivismo de escravos e africanos como praticantes da luta Capoeira neste período. Inclusive, é no ano de 1811, muito próximo da publicação do referido dicionário, em que é possível constatar, no Rio de Janeiro, a primeira evidencia documental ${ }^{18} \mathrm{da}$ existência da Capoeira jogo-luta.

Mas o que torna esta fonte ainda mais curiosa é a data da publicação do referido dicionário, 1813, período de grande rebuliço em Portugal devido à invasão de Napoleão Bonaparte. Este também é um ponto que merece maiores consideraçóes. Uma análise na fonte primária deste documento poderá fornecer maiores possibilidades para pesquisa.

Há outro ponto interessante envolvendo a data e o local de publicação deste dicionário, pois se pode calcular que para o autor publicar nesta data e local, o mesmo teria verificado e escrito sobre o assunto, no mínimo, na primeira década do século XIX, período uma década antes onde se pode verificar os primeiros indícios do jogo-luta da Capoeira ${ }^{1}$. Também parece ser interessante o tipo de informaçôes que o autor fornece, diferente da dos aparatos de registros da época, característico dos organismos de repressão, que têm uma forma peculiar de interpretaçáo e relato.

Talvez, esta referência do dicionário em Lisboa, 1813, seja um possível elo entre uma matriz indígena da Capoeira e outra matriz praticada por negros no Brasil, ou seja, uma possível matriz principal de muitas outras matrizes que vieram compor a Capoeira. Ou ainda poderia mostrar uma outra face da Capoeira, que poderia também ser um saber corporal de indígenas, mas estes, além de poderem existir em menor número em comparaçáo à populaçáo negra no Rio de Janeiro do século XIX, não teriam um embate evidente contra o 
Estado e o sistema opressor da escravidáo no ambiente urbano, como parte dos negros tinham naquele período, e por isso, não poderiam ser identificados em estudos baseados em prisóes, processos jurídicos, relatos de cronistas, entre outros. Também é possível sugerir que poderia existir outra prática com o mesmo nome ou haver uma confusão na interpretação de práticas diferentes com a mesma nominação.

Entretanto, verificando o "Dicionário da língua portuguesa composto pelo padre D. Rafael Bluteau, reformado, e acrescentado por Antonio de Moraes Silva natural do Rio de Janeiro. Volume 1: A - K”16, assim como também o segundo volume ${ }^{17}$, que trata das letras L à letra $Z$, não foi possível constatar as mesmas consideraçóes que RochA ${ }^{14}$ afirma existirem no dicionário de 1813, desenvolvido também por Antonio de Moraes Silva.

No dicionário do século XVIII ${ }^{16,17}$ é possível encontrar termos como: capoeira, capoeirão, capoeiro, jogado, jogador, jogar, jogo, joguetar, joguete, joguetear e joguinho. Mas nenhum deles faz referência ao jogo-luta. Somente o termo jogar apresenta algo em torno do manejo de armas, mas sem conexóes com a Capoeira. Também pesquisei por termos como: cabeçada, cabecear, luta, lutador e lutar, mas nada encontrei que pudesse corroborar para os mesmos apontamentos que RochA ${ }^{14}$ apresentou.

Neste sentido, tais constataçóes reforçam a possibilidade de que a Capoeira tenha realmente seu período de eclosão no início do século XIX, no Rio de Janeiro, como a grande maioria das fontes ${ }^{18} \mathrm{e}$ pesquisas ${ }^{1-2}$, até o momento, apontam.

Por fim, no intuito de apresentar maiores detalhes sobre os dicionários em questão, os dois volumes ${ }^{16-17}$ editados ao final do século XVIII foram impressos, da mesma forma que o dicionário do início do século XIX ${ }^{14}$, em Lisboa, mas pela "Officina de Simáo Thaddeo Ferreira"16-17. Já o dicionário de 1813 teria sido impresso, segundo RochA ${ }^{14}$, pela Typografhia Lacerdina.

As referências e discussões acima são as que mais pesam ao lado da origem indígena da Capoeira, e que deveriam ser mais bem aprofundadas em sua pesquisa documental e em sua respectiva análise, em futuras pesquisas. Talvez, num futuro próximo, por meio dos apontamentos elaborados neste estudo e de outros similares, pesquisas sejam realizadas nesta vertente, ampliando o conhecimento sobre o tema, já que também são nos países que tiveram um papel ativo na condição de colonizadores, principalmente em Portugal, no caso de se estudar o Brasil, onde podem ser encontradas possíveis significativas referências e, provavelmente, serem produzidas outras contribuições científicas.

O fato de a Capoeira ter raízes indígenas é difícil comprovar, e um dos fatores que contribuem para isto é o massacre cultural e genético que os índios brasileiros sofreram, sendo várias tribos e culturas extintas e suas identidades perdidas, culturas mortas que perfazem uma grande parcela desconhecida pelo meio acadêmico. Faz pouco tempo que foram descobertas na Amazônia ruínas de uma civilização considerada avançada, e ainda, em meados de 2008 encontraram um grupo de índios próximo à fronteira do Brasil com o Peru, que nunca tiveram contato com a civilização, o que comprova ainda um grande desconhecimento sobre uma parte dos povos ameríndios. Assim como vários segmentos da cultura brasileira sofreram influências e contribuiçóes indígenas, é provável que a Capoeira tenha também recebido a sua parcela de contribuição, mesmo que de forma indireta e distante.

Outra fonte que não poderia deixar de ser citada é o romance do final do século XIX Os Capoeiras', de Plácido de Abreu, onde pode ser encontrada a pioneira preocupação quanto à origem da Capoeira. SoAres ${ }^{5}$ cita um trecho da obra de Abreu:

É um trabalho difícil estudar a capoeiragem desde a sua raiz primitiva por que não é bem conhecida a sua origem... Aos nossos índios também não se pode atribuir porque apesar de possuírem a ligeireza que caracteriza os capoeiras, contudo, não conhecem os meios que estes empregam para o ataque e a defesa. O mais racional é que a capoeiragem criou-se, desenvolveu-se e aperfeiçoou-se entre nós (p.10)5.

Plácido de Abreu em sua obra retrata a origem da Capoeira, segundo sua visão no final do século XIX, no Rio de Janeiro, como "um trabalho difícil estudar", ideia que permanece atualizada devido à carência de fontes expressivas. Também não atribui tal origem ao "preto africano" e nem ao índio. É possível pensar que já no final do século XIX no Rio de Janeiro não havia índios em tribos organizadas e próximas ao centro urbano, com seus rituais originais preservados para que Plácido de Abreu pudesse realmente fundamentar o que escreveu, pois mesmo que tivesse uma relativa quantidade de índios no centro urbano da capital do Brasil neste período, seria mesmo assim uma pequena parcela da ampla e diversificada representaçáo dos índios do Brasil. O Rio de Janeiro foi um dos principais pontos de colonização e, portanto, local onde houve um rápido declínio da populaçáo e ocupação indígena, sobretudo pela característica guerreira de 
alguns povos nativos, que foram amplamente combatidos, como dito anteriormente. Por fim, Plácido de Abreu generaliza as várias etnias de índios em uma só e descreve os Capoeiras como um tipo social, com meios de ação e conduta próprios.

Mas também há de se considerar que o centro do Rio de Janeiro no século XIX era uma grande babel de cultura, pessoas, grupos e expressōes. Neste sentido, não seria impossível a transmissibilidade de algum tipo de cultura indígena para a Capoeira existente durante este período. Neste sentido, SOAREs ${ }^{2}$ afirma que: Algumas vezes, os índios vinham para servir como soldados "voluntariamente". Pontos extremos do Império, como Rio Grande do Sul e Pará, forneceram braços nativos para os trabalhos do Arsenal, contribuindo assim para forjar a imagem da Torre de Babel que o Arsenal da Marinha tinha naquela época. Quase um microcosmo do Brasil imperial em seus primórdios (p.277).

O Arsenal da Marinha foi um dos principais locais de aglutinação de presos por capoeira na primeira metade do século XIX - como Soares ${ }^{2}$ demonstrou em seu trabalho - que também deixou de ser apenas um local de punição e passou a ter "um papel central na socialização escrava e nas trocas entre escravos e homens do mar" (p.275)2.

Reiteradas vezes, a documentação do Arsenal relata

a presença de indígenas na ilha, geralmente traba-

lhando como remadores. Certa feita, um grupo de índios, recrutados a pedido do ministro da Marinha para servirem como remadores e vindos de pontos tão distantes como Alagoas, Bahia e Cabo Frio, após uma desavença com o responsável pelo "Aparelho" (pessoal do Arsenal), simplesmente regressou para suas aldeias, sendo declarado desertor (p.277) ${ }^{2}$.

De acordo com documento do Arsenal, datado de 9 de janeiro de 1827, as aldeias para onde os índios voltaram eram em Alagoas, Bahia, Mangaratiba, Itaguaí, Cabo Frio, São Gonçalo, São Lourenço e Vila $\mathrm{Nova}^{2}$ (p.316). Também no Livro do mestre de escravos, o qual apontava uma grande variedade na população escrava do complexo do Arsenal, consta a relaçáo de 14 índios do Pará trazidos para a Marinha e um grupo de índios guaranis que se ofereceram "voluntariamente" para serem assentados como praças na Imperial Brigada de Artilharia da Marinha ${ }^{2}$ (p.282, 316). Tal fato demonstra claramente a imensa possibilidade de trocas de informações e culturas entre escravos, militares, homens do mar e indígenas de diferentes aldeias do Brasil.

Há também outras especulações em relação à origem indígena da Capoeira que são baseadas na origem etimológica do vocábulo capoeira. Tratam-se de indícios etimológicos indígenas para o vocábulo e concomitantemente para a Capoeira luta, prática sócio corporal, sugerindo ao menos, uma origem nominal para a prática.

Sobre a origem do vocábulo capoeira, de acordo com as fontes, este estava presente tanto na cultura Tupy-Guarany como na portuguesa, quando começa a ser verificado pela cultura europeia ocidental. Como um mesmo vocábulo com significados tão próximos pode ter surgido em dois lugares distantes e diferentes? Pode-se afirmar que o termo seja originário da cultura Tupy-Guarany, e que foi absorvido pela cultura portuguesa após o início da colonização do Brasil. Com certeza a origem do vocábulo capoeira é outro ponto que poderia ser pesquisado para se obter maiores esclarecimentos sobre o assunto e consequentemente sobre a origem nominal da Capoeira. Mas é possível inferir que o vocábulo originário da cultura Tupy-Guarany foi absorvido pela cultura portuguesa após o início da colonização do Brasil devido ao seu primeiro registro na língua portuguesa em 1577, por meio do Padre Fernão Cardim (SJ), na obra "Do clima e da Terra do Brasil", com a conotaçáo de vegetação secundária, roça abandonada (p.1.44) ${ }^{24}$.

Segundo ARAÚJO ${ }^{12}$, no contexto vocabular popular brasileiro, o vocábulo capoeira guarda os seguintes significados: como qualificaçáo de indivíduos fugitivos; como qualificaçáo de toda a sorte de indivíduos malfeitores; e como qualificação de indivíduos que praticavam ou exerciam a luta ou o jogo da Capoeira. Deste modo, o fato do vocábulo capoeira ter diferentes significados, teria contribuído para uma confusão em relação ao significado da prática do jogo-luta e os outros significados da palavra. $\mathrm{O}$ autor também afirma que semelhante confusão aconteceu acerca da palavra negro, pois eram considerados negros todos cuja pele não fosse branca. Sabe-se que mesmo se a pele de um indivíduo fosse branca, mas se a legitimidade da sua descendência branca fosse contestada, este indivíduo poderia não ser considerado branco. Por tais razóes, nos dois primeiros séculos do Brasil colônia, tantos os negros, negros da Guiné, oriundos da África, como os negros da terra, os índios brasileiros, eram chamados de negros, sendo indivíduos considerados escravos ${ }^{12}$ (p.39-40). Portanto, ao se analisar algum documento deste período o pesquisador deve estar atento para suas interpretaçôes não serem confundidas por meio da generalização do termo.

Esta não distinção pode ter sido aplicada aos negros capoeiras presentes em fontes do início do século XIX. Sobre a utilização do termo capoeira, ARAújo ${ }^{12}$ afirma que: 
No que tange à utilização deste termo para a designação dos indivíduos de má índole, creio ter ela surgido paralelamente à identificação dos indivíduos fugitivos desde a época colonial, atravessando, assim, vários períodos históricos e consolidando-se mais fortemente durante o século XIX, de acordo com registros jurídicopoliciais sobre os indivíduos dos grupamentos marginais, em particular os escravos e malfeitores aquilombados nos arredores da cidade ou mesmo os residentes na malha urbana, incluindo, entre eles, aqueles que praticavam os exercícios de agilidade e destreza corporal como forma de defesa pessoal ou como atividade lúdica (p.42).

Analisando os significados do vocábulo capoeira, é possível supor, apoiado nas considerações de ARAújo ${ }^{12}$, que a origem do termo capoeira para malfeitores de toda a ordem teria surgido de homens que saíam de fossos e matas ao longo dos caminhos ermos para praticar delitos - como os capoeiras que atacavam pedestres ou escoltas de presos -, voltando em sua fuga para se esconder novamente na capoeira-mata, das quais tais tipos poderiam ainda perpetrar diversas outras açóes semelhantes, também se escondendo em tais lugares, estigmatizando negativamente tal vocábulo.

Desta maneira, não seria estranho a associação da prática - não tolerada - do jogo-luta da Capoeira a um ou mais tipos sociais negativos e repreendidos pelas autoridades, mas tendo a denominação de capoeiras em comum:

Acreditando que as autoridades jurídico-policiais, ao identificarem uma prática corporal de caráter lúdico ou mesmo de luta e desconhecendo sua origem e denominação, por certo, vincularam-na diretamente aos indivíduos dos grupos marginais (capoeiras) que as realizavam, depreendendo-se daquela manifestação de agilidade e destreza corporal que lhes apresentava como sendo uma luta/jogo de capoeiras, evidenciando-se preponderantemente, neste caso, o vocábulo designativo de tais personagens como determinante para a qualificação nominal da coisa. [grifos no original] (p.59) ${ }^{12}$.

Deste modo, pode-se acreditar que a terminologia atribuída a este tipo social passou a ser relacionada aos diversos comportamentos e atitudes de toda a sorte de fugitivos, malfeitores, vadios, turbulentos, desordeiros, tumultuadores, assassinos, agressores, ladróes e de outros tipos - como os negros e escravos que tanto causavam a desordem urbana no início do século XIX no Rio de Janeiro.

Enfim, é possível concordar com uma das conclusões que Araújo ${ }^{12}$ chegou:
Pela configuração metonímica, onde a identificação terminológica atribuída aos malfeitores de toda a ordem foi relacionada com os exercícios de agilidade e destreza corporal, como fundamento teórico para a atribuição nominal desta manifestação corporal (a atribuição nominal dos indivíduos passou para uma prática a eles relacionada) (p.63).

Esta contribuição de ArAúJo ${ }^{12}$ é derivada de apontamentos inicialmente feitos por BRETAS ${ }^{25}$, por Holloway $^{26}$ e por Vieira e AssunÇÃo ${ }^{13}$. Portanto, estudos sobre a Capoeira devem levar em conta esta generalização do vocábulo, tanto para o jogo-luta como para o tipo social, em determinadas fontes e períodos. Falhas na definição e delimitação terminológica e conceitual, e do contexto e concepção do vocábulo, podem chegar a comprometer algumas narrativas ou construçóes teóricas.

Nas pesquisas que abordam a história da Capoeira existem discussóes e diferentes posiçóes dos pesquisadores referentes às interpretações etimológicas do vocábulo capoeira e ao emprego do mesmo, o qual pode ser encontrado em documentos a partir do final do século XVI. A Capoeira como prática corporal - luta e jogo - começou a ser documentada na segunda década do século XIX no Rio de Janeiro ${ }^{1-2}$. Antes disso, é possível encontrar a generalização do vocábulo capoeira tanto para designar o praticante do jogo-luta, como também malfeitores, ladróes e bandidos de toda ordem, como já afirmado ${ }^{12}$.

Sob esta perspectiva metodológica, pesquisas sobre a Capoeira em períodos antes do século XIX tornam-se difíceis devido a possível ausência de fontes que possibilitariam interpretações fidedignas. De todo modo, é possível crer na possibilidade da prática da Capoeira como luta-jogo ao final do século XVIII no Rio de Janeiro, mesmo que esta ausência de fontes e as referências ${ }^{27-29}$ que existem sobre este período não possam corroborar esta afirmação com rigor metodológico-científico.

Considerando os apontamentos acima, é possível afirmar que a maior e mais certa contribuição indígena para a Capoeira, mesmo que de forma indireta, é o próprio nome dado à prática, termo originário do Tupy-Guarany. De todo modo, seria interessante que outras pesquisas fossem feitas neste sentido, pois como já afirmado, além do tronco linguístico Tupy, o vocábulo capoeira poderia estar presente com o mesmo ou com um diferente significado, ou ainda de outra forma, nos outros três principais troncos linguísticos indígenas do Brasil: Je, Aruak e Karib. Mais considerações devem ser levantadas sobre esta vertente de estudo. 
Foram apresentados no decorrer deste trabalho alguns possíveis argumentos sobre a origem indígena da Capoeira com suas respectivas restriçóes. Como se pode observar, a possibilidade de uma origem indígena do jogo-luta ou as suas contribuiçóes como uma das matrizes que vieram a compor a Capoeira ainda está por ser desvendada ou ao menos, melhor especulada. No entanto, deve-se lembrar que no decorrer das últimas décadas estas ideias geraram discursos e influenciaram, de uma maneira ou de outra, o imaginário social capoeirístico, diferentes identidades na Capoeira, e a formação do capoeirista na qual é conhecida. Consequentemente, também definiu, possivelmente, as bases da memória cultural e sócio motora contemporânea de alguns grupos no campo da Capoeira.

Foi possível concluir que o perfil étnico dos praticantes da luta e do jogo da Capoeira no início do século XIX demonstra que, apesar de ser encontrado um perfil predominantemente de escravos e africanos ${ }^{2}$, não se pode inferir de imediato que a gênese desta expressão seria uma cultura e prática de um grupo, de uma etnia ou de uma naçáo africana específica.

É possível que discursos que se antagonizam quanto as etnias que compuseram o processo que originou a Capoeira, de certo modo, venha esvaziar a essência da história do desenvolvimento do jogo-luta como a maior forma de expressão do inconformismo escravo no Brasil, como verificado por Soares ${ }^{2,5}$. Afirmar uma possível origem indígena da Capoeira também nega ou dilui as origens escravas do jogo-luta. Conforme afirmou AssunçÃO ${ }^{30}$ (p.27-28), tal discurso de ancestralidade indígena da Capoeira emerge de uma certa noçáo de brasilidade oriunda do ideal de autenticidade brasileira pela mestiçagem da nação:

A invenção de uma ancestralidade indígena, confor-

me o modelo romântico do século XIX, oferecia a

vantagem de conferir um caráter mais nobre (como

o bom selvagem da ilustração setecentista) e mais

autenticamente brasileiro à capoeira. Além do mais

a inclusão de algum elemento indígena nas origens

da arte se enquadra melhor com a ideia fixa de que

tudo o que é autenticamente brasileiro provém da

mestiçagem entre as 'três raças' formadoras (p.28).

Destarte, é necessário considerar a possibilidade da presença não só de negros, mas também de índios e mestiços na prática da Capoeira pelo fato de que em 1813, em Lisboa, ter sido publicado um dicionário afirmando isto, conforme aponta RochA ${ }^{14}$. Maiores estudos sobre o conteúdo desta obra devem ser realizados para um aprofundamento na questão, já que o mesmo autor, em edição de dicionário ${ }^{16-17}$ anterior, ao final do século XVIII, não sugeria tal indicação.

Por meio deste estudo foi concluído que não é possível afirmar uma origem da Capoeira oriunda somente por uma matriz étnica indígena ou de uma expressão cultural indígena específica, e nem mesmo de uma expressão genérica, assim como não é possível afirmar uma origem indígena da Capoeira ou proposta teórica consistente neste sentido. Contudo, foi verificado ser possível que a Capoeira possa ter influências indígenas brasileiras ou mesmo ter uma matriz indígena, como já discutido no texto. Certa é a contribuição nominal do vocábulo capoeira para o jogo-luta, de origem linguística indígena, mais precisamente Tupy.

Um possível caminho de pesquisa ainda por ser percorrido é a investigação sobre a possibilidade da troca de experiências e saberes culturais entre índios e negros que cumpriam pena em trabalhos forçados. Neste sentido, estudos podem ser realizados na tentativa de obter indícios da presença de índios junto aos capoeiras presos no Rio de Janeiro, a partir de 1808, quando os índios podem ter contribuído de alguma forma no desenvolvimento da Capoeira no Rio de Janeiro durante o século XIX.

É sensato afirmar que a dificuldade em pesquisar a origem da Capoeira não está na exclusividade de sua gênese, mas sim na diversidade que a compôs. Existem vários pontos, descritos ao longo desta pesquisa, que se forem melhor e mais esclarecidos, podem somar substancialmente e sugerir novos caminhos para pesquisa, principalmente, a pesquisa em algumas das fontes primárias que não foram possíveis de serem utilizadas neste trabalho. Pesquisadores de outras áreas, principalmente das Ciências Humanas e Sociais, podem somar esforços neste sentido. Baseados nisto, sugere-se que o assunto ainda demanda mais pesquisas e não se encontra encerrado.

Como visto, devido à proximidade entre índios e negros, existiu grande possibilidade de trocas e influências culturais entre grupos diversos, sugerindo, deste modo, em uma maior possibilidade de agregação de elementos indígenas na Capoeira após o contato com a cultura dos homens branco e negro. Entretanto, até o momento, somente é possível afirmar que a maior e mais certa contribuição indígena para a Capoeira, mesmo ocorrendo de forma indireta e passiva, é a origem nominal da prática, termo originário do Tupy-Guarany. 


\title{
Notas
}

a. Johan Jacob Nieuhof teria sido um viajante neerlandês e a sua obra teria sido Memorável Viagem Maritima e Terrestre ao Brasil, Amsterdan, 1682. Estas informaçôes constam no dicionário eletrônico wikipédia, baseado em: Gaspar L. Viajantes em terras brasileiras: documentos existentes no acervo da Biblioteca Central Blanche Knopf. Recife: Fundação Joaquim Nabuco. Parecem ser escassas as informaçôes sobre este cronista, as únicas dentro da possibilidade de tempo e local para pesquisa foi em Wikipédia, a enciclopédia livre. Fonte: Wikipédia. Johan Jacob Nieuhof [homepage na Internet] [citado 21 nov. 08 Nov 21] Disponível em: http://pt.wikipedia.org/wiki/Johan_Nieuhof.

b. A data desta obra é colocada de modo diferente nas obras de SoAres ${ }^{2,5}$, que afirma datar de 1886, na obra de Araújo ${ }^{15}$ está como de 1894-95, e na obra de Lopes " “19_". André Luiz Lacé Lopes 6 relatou ao autor deste artigo, que solicitou a cópia da obra de Plácido de Abreu na Biblioteca Nacional no Rio de Janeiro a um funcionário, pois a obra estava em péssimo estado de conservação, mas, justamente, a página da data de publicaçáo não foi copiada [informação verbal].

\begin{abstract}
Speculations on the possibilities of indigenous origins of capoeira and on the contributions of this cultural matrix on the development of the game-fight

The origin of Capoeira has been investigated and discussed until today. Several researchers in different fields and even capoeiristas themselves disagree about its genesis. These dichotomies persist in clashes in the field of Capoeira. In this article the assumptions about the indigenous Capoeira, and the possible contributions of Brazilian Indians in the development of game-fight.were analyzed, interpreted and discussed. Literature and documents were used as methodological procedure and a qualitative analysis of the sources that were interpreted and discussed throughout the narrative of this work was done. It was found that there was the possibility of interaction between blacks and Indians in cultural exchanges that would allow influences in the development of Capoeira. However, it was concluded that it is not possible to say that there are Brazilian indigenous contributions to the origins of Capoeira. Thus, we can say that the only and important Brazilian indigenous contribution is the nominal origin of the practice, for having the word capoeira tupy source. It is recommended that future studies are accomplished using the notes made in this article and analyzing primary sources that were not possible to be included in this paper.
\end{abstract}

KeY Words: Capoeiragem; Genesis; History; Indians; Game; Fight.

\section{Referências}

1. Lussac RMP. “Da cabeça aos pés”: a origem da capoeira: novos olhares sobre a gênese de um patrimônio cultural do Brasil [dissertação]. Rio de Janeiro (RJ): Universidade Castelo Branco; 2009.

2. Soares CEL. A capoeira escrava e outras tradiçôes rebeldes no Rio de Janeiro 1808-1850. 2a ed. Campinas: Centro de Pesquisa em História Social da Cultura/UNICAMP; 2002.

3. Assunção MR. Capoeira: the history of an Afro-Brazilian martial art. London: Routledge; 2005.

4. Desch Obi MTJ. Angola e o jogo de capoeira. Rev Contemp Ant. 2009;24:103-24.

5. Soares CEL. A negregada instituição: os capoeiras na corte imperial 1850-1890. Rio de Janeiro: Access; 1999.

6. Lopes ALL. A capoeiragem no Rio de Janeiro: primeiro ensaio - Sinhozinho e Rudolf Hermanny. Rio de Janeiro: Europa; 2002.

7. Passos Neto NS. Capoeira: os fundamentos da malícia. 8a ed. Rio de Janeiro: Record; 2001.

8. Vieira LR. Notas sobre danças de combate e lutas africanas. Rev Prat Capoeira. 2003;22:10-1.

9. Vieira LR. Notas sobre danças de combate e lutas africanas: III. Rev Prat Capoeira. 2003;23:10-1.

10. Vieira LR. Notas sobre danças de combate e lutas africanas: IV. Rev Prat Capoeira. 2003;24:10-1. 
11. Vieira LR. Capoeira: tradiçôes e identidades. Rev Prat Capoeira. 2005;29:30-1.

12. Araújo PC. Capoeira: um nome - uma origem. Juiz de Fora: Notas \& Letras; 2005.

13. Vieira LR, Assunçáo MR. Mitos, controvérsias e fatos: construindo a história da capoeira. Estud Afro-asiát. 1998;34:81-121.

14. Rocha LCK. Teses que comprovam a brasilidade da capoeira. Rev Prat Capoeira. 2002;17:10-3.

15. Araújo PC; Jaqueira ARF. Do jogo de imagens às imagens do jogo: nuances de interpretação iconográfica sobre a capoeira. Coimbra: Centro de Estudos Biocinéticos/Faculdade de Ciências do Desporto e Educaçáo Física; 2008.

16. Bluteau R. Dicionário da língua portuguesa composto pelo padre D. Rafael Bluteau, reformado, e acrescentado por Antonio de Moraes Silva natural do Rio de Janeiro. Lisboa: Officina de Simão Thaddeo Ferreira; 1789. Volume 1: A-K [documento na Internet]. [citado 5 nov 2013]. Disponível em: http://www.brasiliana.usp.br/bbd/ handle/1918/00299210\#page/1/mode/1up.

17. Bluteau R. Dicionário da língua portuguesa composto pelo padre D. Rafael Bluteau, reformado, e acrescentado por Antonio de Moraes Silva natural do Rio de Janeiro. Lisboa: Officina de Simâo Thaddeo Ferreira; 1789. Volume 2: L-Z [documento na Internet]. [citado 5 nov 2013]. Disponível em: http://www.brasiliana.usp.br/bbd/ handle/1918/00299220\#page/1/mode/1up.

18. Brasil. Arquivo Nacional. Códice 403. Vol I. 5 jun. 1811.

19. Silva GO. Capoeira do engenho à universidade. 2a ed. São Paulo: o autor; 1995.

20. Abreu FJ. Capoeiras: Bahia, séc. XIX: imaginário e documentação. Salvador: Instituto Jair Moura; 2005. Vol. 1.

21. Rugendas JM. Viagem pitoresca através do Brasil. Milliet S, tradutor. Belo Horizonte: Itatiaia; 1998. (Coleção Reconquista do Brasil; série 3; vol. 8).

22. Freire AD. João VI e a guerra sem fim contra os índios botocudos. J Cidadania. 2008;14:4-5.

23. Gomes L, Nogueira M. O Brasil surreal que Dom João encontrou. Rev Super Interessante. 2008;251:62-71.

24. Da Costa L, organizador. Atlas do esporte no Brasil. Rio de Janeiro: CONFEF; 2006.

25. Bretas ML. Navalhas e capoeiras: uma outra queda. Ciênc Hoje. 1989;59:239-56.

26. Holloway TH. O saudável terror: repressão policial aos capoeiras e resistência dos escravos no Rio de Janeiro no século XIX. Estud Afro-asiát. 1989; 16:129-40.

27. Araújo E. Estudo histórico sobre a Polícia da Capital Federal de 1808 a 1831: primeira parte. Rio de Janeiro: Imprensa Nacional; 1898.

28. Cavalcanti NO. Crônicas históricas do Rio colonial. Rio de Janeiro: Civilização Brasileira; 2004.

29. Edmundo L. O Rio de Janeiro no tempo dos Vice-Reis. 2a ed. Rio de Janeiro: Athena; 1940.

30. Assunção MR. Da "destreza do mestiço” à "Ginástica Nacional”: narrativas nacionalistas sobre a capoeira. Rev Contemp Ant. 2009;24:19-40.

\section{Agradecimentos}

Esta pesquisa foi realizada com recursos do CNPQ, por meio de bolsa de doutorado.

\begin{tabular}{r|l} 
ENDEREço & \\
Ricardo Martins Porto Lussac & \\
Programa de Pós-Graduação em Educação (ProPEd) & Recebido para publicação: 16/05/2013 \\
Universidade do Estado do Rio de Janeiro & 1a. Revisão: 13/11/2013 \\
R. São Francisco Xavier, 524 - Grupo 12.037-F & 2a. Revisão: 14/10/2014 \\
20550-013 - Rio de Janeiro - RJ - BRASIL & Aceito: 14/10/2014 \\
e-mail: ricardolussac@yahoo.com.br & \\
&
\end{tabular}

278 • Rev Bras Educ Fís Esporte, (São Paulo) 2015 Abr-Jun; 29(2):267-78 